Jurnal

\title{
Ruptured Aneurysm of Sinus of Valsalva Into the Right Ventricle: The Role of Echocardiography
}

\author{
Primawati A, Krisdinarti L, Mumpuni H
}

Departemen Kardiologi dan Kedokteran Vaskular, Universitas Gadjah Mada / RSUP Dr. Sardjito, Yogyakarta, Indonesia
Background: Aneurysm sinus valsavamerupakan rare anomaly covering only $1 \%$ of the incidence of congenital cardiac anomalies. The most frequent complication is rupture into the right ventricle, causing a shunt from left to right or aortic valve insufficiency with congestive heart failure requiring immediate surgical management. Echocardiography is a diagnostic modality that can be used to help diagnose the presence of sinus Valsalva aneurysm and complications.

Clinical case: A 35 years old man with complaints dating dyspnoea on exertion and swelling in both legs. Cardiac auscultation obtained their continuous noisy grade III / VI in the lower left sternal border. Electrocardiography showed sinus tachycardia tachycardia with right axis deviation, right ventricular hypertrophy, and ventricular extrasystoles. Transthoracic echocardiography (TTE) and transesophageal echocardiography (TEE) shows an overview of the sinus of Valsalva aneurysm rupture to the right of the right ventricle.

Discussion: When on the clinical findings led to the suspicion rupur sinus of Valsalva aneurysm, the evaluation can be performed using TTE, TEE, Magnetic Resonance Imaging (MRI), maupunkateterisasi heart. Gold standard diagnosis of ruptured sinus Valsalva aneurysm is a cardiac catheterization, but with the advancement of a new generation of engines echocardiography, TTE and TEE has played an important role in the diagnostic confirmation of sinus of Valsalva aneurysm rupture.

Conclusion: Echocardiography is the diagnostic modality that is quite helpful in making the diagnosis, complications and surgical therapeutic options in cases of ruptured sinus of Valsalva aneurysm.

(J Kardiol Indones. 2016;37:33-7)

Keywords : Sinus of Valsalva - Ruptured aneurysm - right ventricle - transthoracic echocardiography - transesophageal 
Jurnal

Kardiologi Indonesia

J Kardiol Indones. 2016;37:33-7

ISSN 0I26/3773

\title{
Ruptur Aneurisma Sinus Valsava Ke Ventrikel Kanan: Peranan Ekokardiografi
}

\author{
Primawati A, Krisdinarti L, Mumpuni H
}

\begin{abstract}
Latar Belakang: Aneurisma sinus valsava merupakan anomali yang jarang terjadi yang hanya meliputi $1 \%$ dari kejadian anomali jantung bawaan. Komplikasi yang paling sering adalah ruptur ke ventrikel kanan, menyebabkan pirau dari kiri ke kanan atau insufisiensi katup aorta dengan gagal jantung kongestif yang memerlukan manajemen bedah segera. Ekokardiografi merupakan modalitas diagnostik yang dapat digunakan untuk membantu mendiagnosis adanya aneurisma sinus valsava maupun komplikasinya.

Kasus klinis: Seorang pria 35 tahun dating dengan keluhan sesak saat aktivitas dan bengkak pada kedua kaki. Pemeriksaan auskultasi jantung didapatkan adanya bising kontinu grade III/VI di batas sternum kiri bawah. Elektrokardiografi menunjukkan takikardia sinus takikardia dengan deviasi aksis ke kanan, hipertrofi ventrikel kanan, dan ventrikel ekstrasistol. Ekokardiografi transtorakal (TTE) dan ekokardiografi transesofageal (TEE) menunjukkan gambaran aneurisma dari sinus Valsava kanan yang ruptur ke ventrikel kanan.

Diskusi: Apabila dari temuan klinis mengarah ke kecurigaan adanya rupur aneurisma sinus Valsava, maka evaluasi dapat dilakukan menggunakan TTE, TEE, Magnetic Resonance Imaging (MRI), maupun kateterisasi jantung. Baku emas diagnosis adanya ruptur aneurisma sinus Valsava adalah kateterisasi jantung, tetapi dengan kemajuan generasi baru mesin ekokardiografi, TTE dan TEE telah memainkan peran penting dalam konfirmasi diagnostik ruptur aneurisma sinus Valsava.

Kesimpulan: Ekokardiografi merupakan modalitas diagnostik yang cukup membantu dalam menegakkan diagnosis, komplikasi maupun pilihan terapi bedah pada kasus ruptur aneurisma sinus Valsava.
\end{abstract}

(J Kardiol Indones. 2016;37:33-7)

Kata kunci: Sinus Valsava, Ruptur aneurisma, Ventrikel kanan, Transtorakal ekokardiografi, Transesofageal ekokardiografi

\section{Pendahuluan}

A neurisma sinus Valsava, atau yang dikenal dengan fistula sinus coroner, merupakan dilatasi yang disebabkan karena pemisahan antara tunika media dan annulus katup

Alamat Korespondensi

dr. Primawati A, Departemen Kardiologi dan Kedokteran Vaskular, Universitas Gadjah Mada / RSUP Dr. Sardjito, Yogyakarta, Indonesia. E-mail: addienaprima@gmail.com aorta. Kelainan ini jarang terjadi dengan kejadian hanya $1 \%$ dari kelainan jantung kongenital. ${ }^{1}$ Penyebab paling sering adalah kongenital, meskipun dapat merupakan akuisita akibat trauma, infeksi, atau kelainan degeneratif. ${ }^{2} 60 \%$ dari kejadian ruptur aneurisma ini berasal dari sinus Valsava kanan. ${ }^{3}$ Ruptur ke ventrikel kanan merupakan komplikasi yang paling sering terjadi, yang menyebabkan pirau dari kiri ke kanan atau insufisiensi katup aorta dengan gagal jantung akut yang membutuhkan terapi bedah segera. Ruptur aneurisma sinus Valsava dapat didiagnosis 
dengan mudah menggunakan ekokardiografi. Diagnosis dini dan intervensi bedah segera dapat membantu menurunkan morbiditas dan mortalitas. ${ }^{4}$

\section{Kasus}

Laki - laki usia 35 tahun dating dengan keluhan sesak napas yang semakin progresif disertai kedua kaki bengkak sejak 3 bulan sebelum masuk rumah sakit. Pada pemeriksaan fisik didapatkan peningkatan tekanan vena jugularis, bising kontinu grade III/VI pada batas sternum kiri bawah, hepatomegaly, serta edema kaki bilateral. Elektrokardiografi menunjukkan sinus takikardia, dengan deviasi aksis ke kanan, hipertrofi ventrikel kanan, dan ventrikel ekstrasistol. Ronsen toraks menunjukkan gambaran kardiomegali dengan dilatasi semua ruang jantung dan peningkatan corakan vascular paru. Transtorakal Ekokardiografi menunjukkan dilatasi semua ruang jantung dengan fungsi sistolik yang masih baik. Didapatkan gambaran dilatasi aneurismatik dari sinus Valsava kanan yang menonjol ke ventrikel kanan dengan aliran doppler yang turbulen (gambar 1), regurgitasi tricuspid berat yang disertai dengan hipertensi pulmonal berat. Kemudian dilakukan TEE yang mengkonfirmasi adanya ruptur aneurisma sinus Valsava ke ventrikel kanan (gambar 2). Pasien kemudian direncanakan untuk dilakukan manajemen bedah segera.

\section{Diskusi}

Tiga sinus dari Valsava terletak di bagian paling proksimal aorta, tepat di atas katup aorta. Aneurisma sinus Valsava dapat merupakan kelainan kongenital maupun akuisita yang mungkin disebabkan oleh infeksi, trauma atau degeneratif. ${ }^{2}$ Kelainan ini dapat terkait dengan kelainan kongenital jantung lainnya, seperti defek septum ventrikel pada 30-60\% kasus, kelainan katup aorta seperti insufisiensi aorta pada 20-30\% dari kasus, katup bikuspid (10\%), maupun stenosis aorta $(6,5 \%)$. Kelainan ini juga dapat dikaitkan dengan stenosis paru $(9,7 \%)$, koarktasio aorta $(6,5 \%)$, duktus arteriosus paten $(3,2 \%)$, maupun insufisiensi trikuspid (3,2\%). ${ }^{5}$ Aneurisma sinus Valsava yang masih intak atau belum ruptur biasanya tidak menimbulkan gejala, meskipun demikian, hal ini dapat menyebabkan obstruksi outflow tract dari ventrikel kanan dan iskemia miokard akibat efek kompresi dari aneurisma. ${ }^{6}$

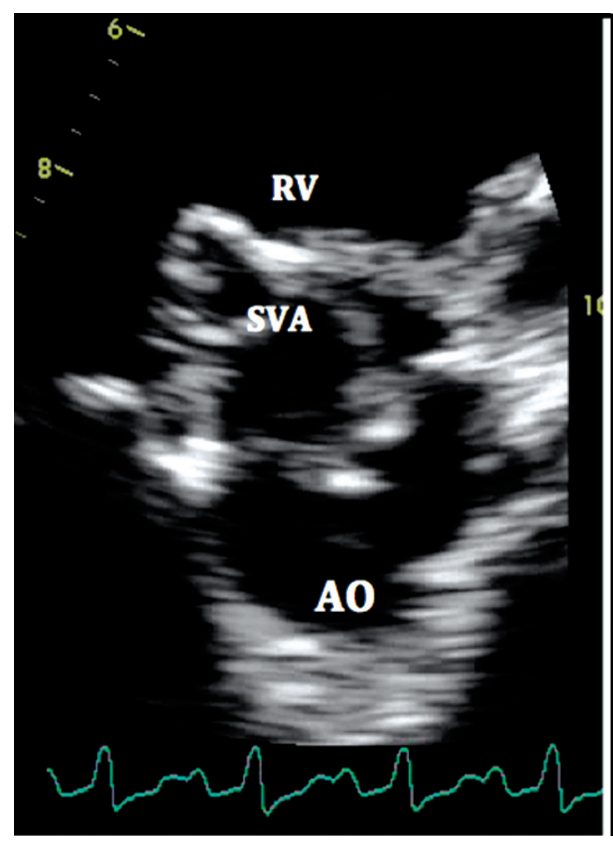

A

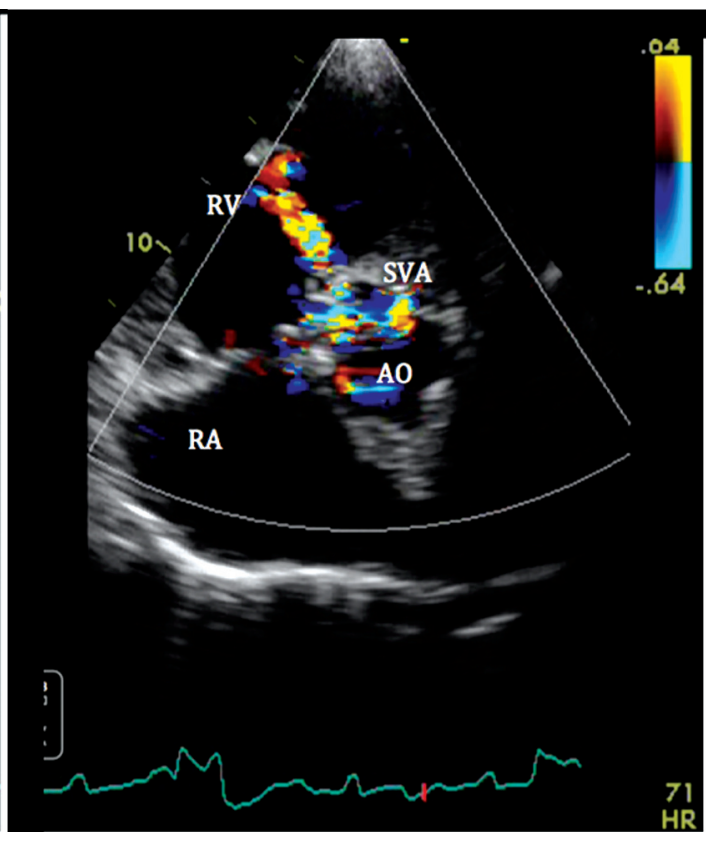

B

Gambar 1. Transtorakal ekokardiografi menunjukkan gambaran "windsock" yang menunjukkan adanya dilatasi sinus Valsava kanan yang ruptur ke ventrikel kanan dilihat dari parasternal long axis (A dan B). 


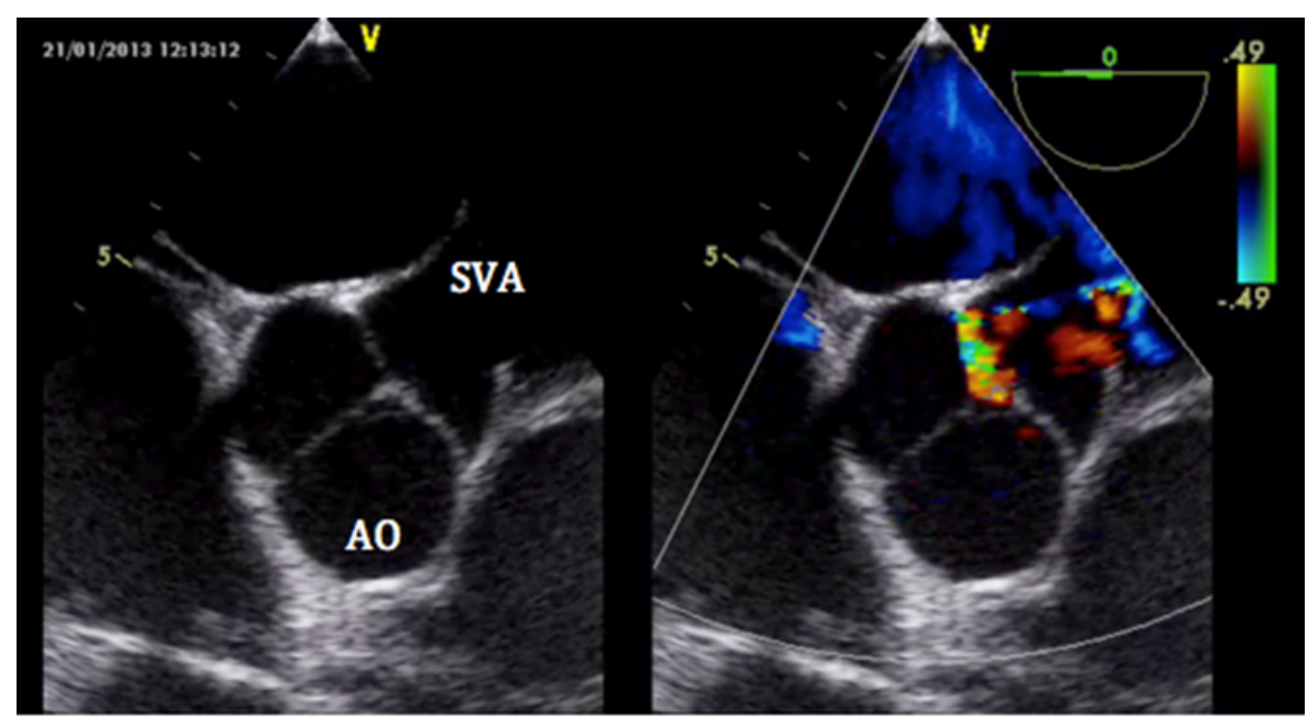

Gambar 2. Transesofageal ekokardiografi mengkonfirmasi adanya ruptur aneurisma sinus Valsava kanan.

Frekuensi ruptur sinus Valsava ini bervariasi sesuai dengan lokasi, yaitu $60 \%$ di sinus Valsava kanan, 42 $\%$ di sinus nonkoronarius, dan hanya $10 \%$ di sinus Valsava kiri. Ruptur dapat terjadi spontan, setelah trauma, latihan fisik ekstrim atau karena endocarditis. ${ }^{7}$ Ruptur dari aneurisma sinus Valsava terjadi terutama ke ventrikel kanan $(60 \%)$ atau atrium kanan (29\%), atrium kiri (6\%), ventrikel kiri (4\%) atau pericardium (1\%). ${ }^{5,6}$ Konsekuensi fisiopatologis dari ruptur ini tergantung pada volume aliran yang melewati ruptur, kecepatan aliran, serta ruang jantung yang terlibat. Apabila proses ruptur terjadi secara tiba - tiba, maka terjadi dekompensasi hemodinamik yang dapat menyebabkan agal jantung akut. ${ }^{7}$ Ruptur yang kecil, gradual, dan progresif dapat ditoleransi sementara, terjadi pada $25 \%$ kasus. ${ }^{8}$ Gejala klinis yang muncul akibat kondisi ini antara lain nyeri dada, sesak napas, batuk, serta edema perifer. Apabila dari klinis dicurigai adanya ruptur aneurisma sinus Valsava, maka dapat dilakukan TTE, TEE, MRI, serta kateterisasi jantung sebagai modalitas diagnostik. ${ }^{9}$

Dahulu kateterisasi jantung merupakan baku emas untuk menegakkan diagnosis ruptur aneurisma sinus Valsava. Kateterisasi jantung digunakan untuk memvisualisasi lokasi ruptur dan melihat patensi arteri koroner. ${ }^{5}$ Dengan perkembangan teknologi ekokardiografi, saat ini TTE dan TEE memiliki peran penting dalam proses diagnosis ruptur aneurisma sinus Valsava. TTE dan TEE memiliki akurasi diagnostik
$75 \%$ dan $90 \%$, baik aneurisma yang ruptur maupun yang tidak ruptur, dapat memvisualisasi ukuran, asal sinus, titik terminasi, tingkat keparahan dan mekanisme insufisiensi katup, adanya kelainan jantung lain yang berhubungan, serta orientasi prosedur pembedahan. ${ }^{10}$ TEE bermanfaat ketika TTE tidak meyakinkan. Selain itu, TEE mungkin sangat membantu untuk definisi anatomi yang lebih baik selama evaluasi pra-operasi. Pandangan parasternal long axis dan short axis (di tingkat root aorta) dianggap terbaik untuk memvisualisasikan aneurisma sinus Valsava. TTE dapat melihat aorta proksimal, sinus, katup aorta, dan struktur sekitarnya. Temuan Doppler dapat mengidentifikasi lokasi shunt yang tepat. Penampakan "windsock" yaitu dilatasi sinus Valsalva adalah gambaran khas dari aneurisma sinus Valsava. fitur Doppler termasuk aliran kecepatan tinggi terus menerus dari aorta ke ruang jantung. Diagnosis biasanya ditegakkan dengan pemetaan aliran Doppler warna. Pemetaan warna aliran Doppler dapat mengungkapkan jet aliran mosaik terus menerus dari aneurisma ke ruang jantung. Pencitraan rinci shortaxis dari outflow tract ventrikel kiri dan aorta root membantu untuk membedakan aneurisma ventrikel septal defek dari aneurisma sinus Valsalva di atas anulus aorta. ${ }^{10}$ pencitraan dari parasternal short-axisjuga dapat membantu membedakan aneurisma sinus Valsava dari fistula arteriovenosa coroner, dimana arteri coroner yang berdilatasi dapat terlihat di dekat aorta. Tatalaksana bedah dapat dilakukan pada pasien berdasarkan 
gambaran TTE maupun TEE, tanpa harus dilakukan kateterisasi jantung. ${ }^{8}$

TEE sangat sensitif untuk identifikasi dan lokasi ruptur aneurisma. TEE mungkin terbukti lebih bermanfaat dalam memvisualisasi ruptur kecil seperti biasanya memungkinkan visualisasi yang lebih baik dari aneurisma dan ruturnya. TEE telah terbukti lebih berguna dalam menilai lesi kongenital yang terjadi bersamaan dengan ruptur aneurisma sinus Valsava, namun tidak lebih superior disbanding TTE maupun angiografi dalam menilai derajat insufisiensi aorta atau pirau dari kiri ke kanan. ${ }^{10}$

\section{Kesimpulan}

Ekokardiografi merupakan modalitas diagnostik yang akurat dalam mendiagnosis ruptur aneurisma sinus Valsava yang dapat membantu identifikasi lokasi ruptur serta evaluasi defek lain yang menyertai, dan dalam beberapa kasus dapat menggantikan angiografi sebagai baku emas diagnosis ruptur aneurisma sinus Valsava.

\section{Daftar Pustaka}

1. Chang, C.C., Chin, C.H., Chin, M.L. 2006. Sinus of Valsalva Aneurysm with Rupturing into the Right Atrium - A Case Report and Review of the Literature. Acta Cardiol Sin; 22:96-101.
2. Vautrin, E., Barone-Rochette, G., Philippe, J. 2008. Rupture of right sinus of Valsalva into right atrium: ultrasound, magnetic resonance, angiography and surgical imaging. Arch Cardiovasc Dis; 101:501-502.

3. Wells, T., Byrd, B., Neirste, D. 1999. Sinus of Valsalva Aneurysm With Rupture Into the Interventricular Septum and Left Ventricular Cavity. Circulation; 100:1843-1844.

4. Shah, R.P., Ding, Z.P., Quek, S. 2001. A ten-year review of ruptured sinus of valsalva: clinico-pathological and echo-Doppler features. Singapore Med J; 42:473-476.

5. Chu, S.H., Hung, C.R., How, S.S., Chang, H., Wang, S.S., Tsai, C.H. 1990. Ruptured aneurysms of the sinus of Valsalva in Oriental patients. J Thorac Cardiovasc Surg; 99:288-298.

6. Harkness, J., Fitton, T., Barreiro, C.J., Alejo, D., Gott, V.L., Baumgartner, W.A. 2005. A 32-year experience with surgical repair of sinus of Valsalva aneurysms. J Cardiac Surg, 20:198204.

7. Sánchez, M., Garcia, M., Quintana, C., Kareh, J. 2006. Heart failure in rupture of a sinus of valsalva aneurysm. Am J Med Sci; 331:100-102.

8. Lobato, E., Greene, M., Malias, M., Gravenstein, N. Intraoperative usefulness of transesophageal echocardiography: detection of unsuspected rupture of an aneurysm of the sinus of Valsalva. J Cardiothorac Vasc Anesth; 11:619-621.

9. Henze, A., Huttunen. H., Bjork, V.O. 1983. Ruptured sinus Valsalva aneurysms. Scand J Thorac Cardiovasc Surg; 17:249253.

10. Malcolm, I. 1996. Unruptured aneurysm of the sinus of Valsalva. Can J Cardiol; 12:783-785. 